\title{
Génesis de la Economía Social desde una perspectiva histórica con especial referencia al marco teórico surgido en Francia
}

\author{
Lidia Valiente Palma ${ }^{1}$ - y María del Carmen Pérez González ${ }^{2}$
}

Recibido: 10 de mayo de 2021 / Aceptado: 20 de julio de 2021 / Publicado: 2 de noviembre de 2021

Resumen. En este trabajo se identifica y sistematiza la evolución seguida, tanto en el pensamiento económico como en los movimientos sociales, desde los siglos XVIII y XIX, de lo que podría considerarse como el surgimiento y la base de la Economía Social actual. En esta identificación se pone especial énfasis en el marco teórico surgido en Francia sobre este concepto, promovido por revoluciones sociales y movimientos filosóficos del momento. La Economía Social se caracteriza por estar formada por organizaciones que desarrollan su actividad en base a una serie de principios y valores sociales, siendo las sociedades cooperativas las más remotas y representativas. Es el cooperativismo, entre otros movimientos sociales y de pensamiento económico que se exponen en el presente trabajo, el desencadenante de lo que hoy se conoce como Economía Social. En este sentido, la contribución de este estudio es la sistematización y puesta en valor de todos estos movimientos históricos como elementos desencadenantes de lo que podría ser el principio de una concepción holística y evolutiva de la Economía Social.

Palabras clave: Economía Social y Solidaria; Francia; Movimiento cooperativo; Pensamiento socioeconómico; Siglo XVIII; Siglo XIX.

Claves Econlit: A13; B00; B55; J54; P13.

\section{[en] Genesis of the Social Economy from a historical perspective with special reference to} the theoretical framework that emerged in France

\begin{abstract}
This work identifies and systematizes the evolution, both in economic thought and in social movements, since the 18th and 19th centuries of what could be considered the emergence and foundation of today's Social Economy. In this identification, special emphasis is placed on the theoretical framework that emerged in France on this concept, promoted by social revolutions and philosophical movements of the moment. The Social Economy is characterized for being formed by organizations that develop their activity based on a series of social principles and values, being the cooperative societies the most remote and representative. It is cooperativism, among other social movements and economic thought that will be presented in this paper, the trigger of the current concept of Social Economy. In this sense, the contribution of this work is the systematization and enhacement of all these historical movements. These movements could be considered as the beginning of a holistic and evolutionary approach of the Social Economy.
\end{abstract}

Keywords: Social and Solidarity Economy; Cooperative movement; France; Socioeconomic thought; 18th century; 19 th century.

Sumario. 1. Introducción. 2. Los precursores de la ES: movimientos sociales y pensamiento socioeconómico en el siglo XIX. 3. Francia en el epicentro del nacimiento de la ES: un marco teórico de referencia. 4. Elementos comunes de la ES y la economía solidaria: el desarrollo de un campo científico a partir de la evolución del pensamiento económico y de los movimientos sociales. 5 . Consideraciones finales. 6. Referencias bibliográficas.

Cómo citar. Valiente Palma, L.; Pérez González, M.C. (2021) Génesis de la Economía Social desde una perspectiva histórica con especial referencia al marco teórico surgido en Francia. REVESCO. Revista de Estudios Cooperativos, vol. 139 , e77447. https://dx.doi.org/10.5209/reve.77447.

\section{Introducción}

La Ley de Economía Social española (Ley 5/2011, de 29 de marzo) define a la Economía Social como el "conjunto de las actividades económicas y empresariales, que en el ámbito privado llevan a cabo aquellas

Universidad de Sevilla, España.

Dirección de correo electrónico: 1valiente@us.es.

2 Universidad de Cádiz, España.

Dirección de correo electrónico: maricarmen.perez@uca.es. 
entidades que, de conformidad con los principios recogidos en el artículo 4, persiguen bien el interés colectivo de sus integrantes, bien el interés general económico o social, o ambos". Estos principios, a los que se hace referencia en esta definición, son el de la primacía de las personas sobre el capital mediante una gestión democrática por parte de sus miembros; la aplicación de los resultados obtenidos en la actividad económica según el trabajo aportado por los socios; la promoción de la solidaridad tanto interna como con la sociedad, fomentando el compromiso con el desarrollo local, la igualdad de oportunidades entre hombres y mujeres, la cohesión social, la inserción de colectivos en riesgo de exclusión social, la generación de empleo estable y de calidad, la conciliación de la vida personal, familiar y laboral y la sostenibilidad; y la independencia respecto a los poderes públicos. De esta forma, estos principios orientadores de su actuación diferencian a estas organizaciones de las que se pueden considerar como empresas convencionales.

Aunque se ha detallado qué se entiende por Economía Social (en adelante, ES) según la ley española al respecto, su definición, así como sus conceptos afines, difieren según el contexto de referencia. Así, los diferentes contextos socioeconómicos son responsables de la diversidad de enfoques concebidos para establecer qué es la ES y qué organizaciones la conforman ${ }^{3}$. Entre estas organizaciones se encuentran las sociedades cooperativas, siendo las más remotas y representativas de la ES, no sólo en España, sino a nivel internacional ${ }^{4}$. En esta línea, la Alianza Cooperativa Internacional (ACI) define a una cooperativa como "una asociación de personas que se unen voluntariamente para satisfacer sus necesidades y aspiraciones económicas, sociales y culturales comunes, por medio de una empresa de propiedad conjunta gestionada democráticamente" (ACI, 1995).

Se puede sostener que el concepto de ES está en constante evolución respondiendo a las distintas necesidades socioeconómicas y ambientales que van surgiendo o que implican la necesidad de una transformación o adaptación de las ya existentes (Tomas-Carpi, 1997). No obstante, todos los enfoques coinciden en resaltar la importancia de los valores sociales como eje de funcionamiento de estas organizaciones. Para comprender este significado actual de la ES, se hace necesario retroceder tiempo atrás hasta los siglos XVIII y XIX, hacia contextos sociales y económicos convulsos. Entonces, surgió, en este sentido, un pensamiento crítico de las estructuras socioeconómicas que raramente respondían a un sistema axiológico.

Desde el siglo XIX, en la búsqueda de repartos equitativos de la riqueza, de la mayor participación de los trabajadores en el producto generado en las economías o en la consecución de la autosuficiencia económica, aparecieron líneas de pensamiento desde el socialismo a la corriente liberal económica, pasando por otros movimientos -de pensamiento y de prácticas- como el sindicalismo, el humanismo o el cuaquerismo, con especial incidencia del movimiento cooperativo, entre otros. Dado que en Francia tuvieron lugar desde finales del siglo XVIII las revoluciones de 1789 y la influencia de movimientos filosóficos, se comenzó a desarrollar la base o el marco teórico de lo que después pasaría a denominarse ES.

Es este movimiento cooperativo el que desencadenó los valores y principios, reconocidos mundialmente, sobre los que basan su actuación las sociedades cooperativas en la actualidad. Estos valores son los de ayuda mutua, responsabilidad, democracia, igualdad, equidad y solidaridad. Los principios son el de asociación voluntaria y abierta, gestión democrática y participación económica por parte de los miembros, autonomía e independencia asegurando el control democrático, fomento de la educación, formación e información, cooperación entre cooperativas e interés por la comunidad (ACI, 1995).

Así, desde lo que puede ser considerado como su origen en el siglo XIX y siguiendo una visión evolutiva de la ES, se pone de manifiesto su capacidad transformadora, de adaptación a diferentes contextos actuales, y con una relación con los entornos a nivel multidimensional (social, económico, institucional, político y ambiental).

A partir de lo anterior, el objetivo del presente trabajo ha consistido en identificar y sistematizar la evolución seguida, tanto en el pensamiento económico como en los movimientos sociales, desde el siglo XIX, de lo que podría considerarse como el surgimiento y la base de la ES actual. Para ello, y en lo que respecta a la estructura del trabajo, en el segundo apartado (tras esta introducción) se presentan los diferentes movimientos sociales y de pensamiento económico del siglo XIX, destacando el papel del cooperativismo, entre otros movimientos. A continuación, en el tercer apartado, se determina por qué la ES ha tenido un importante impulso en Francia, lo que está relacionado con las revoluciones sociales y la influencia de filósofos y economistas desde el siglo XVIII. El cuarto apartado, tomando en consideración lo desarrollado en los dos anteriores, analiza cómo el pensamiento económico y los movimientos sociales han convergido hacia lo que actualmente se conoce como ES, comparando este concepto con otro afín, el de Economía

En el caso español, las organizaciones de Economía Social son las cooperativas, las mutualidades, las fundaciones y las asociaciones que lleven a cabo actividad económica, las sociedades laborales, las empresas de inserción, los centros especiales de empleo, las cofradías de pescadores y las sociedades agrarias de transformación (Ley 5/2011, de 29 de marzo, de Economía Social).

4 Según la Alianza Cooperativa Internacional, en el mundo existen alrededor de tres millones de cooperativas que generan un $10 \%$ del empleo total (https://www.ica.coop/es/cooperativas/datos-y-cifras). 
Solidaria, para poner de manifiesto los elementos comunes de ambos y que tienen su base en el surgimiento de los movimientos sociales y del pensamiento económico aquí desarrollados.

A partir de lo anterior, la contribución de este estudio es la sistematización y puesta en valor de todos estos movimientos históricos como elementos desencadenantes de lo que podría ser el principio de una concepción holística y evolutiva de la ES.

\section{Los precursores de la ES: movimientos sociales y pensamiento socioeconómico en el siglo XIX}

Hay que retroceder hasta la Europa de finales del siglo XVIII y principios del XIX para encontrar el origen de la ES tanto en el pensamiento económico como en la evidencia empírica, siendo ésta fruto de las circunstancias y acontecimientos que tuvieron lugar en la época.

En el siglo XIX se produjo el mayor crecimiento económico sin precedentes impulsado por la Primera Revolución Industrial, que supuso un significativo avance tecnológico que dejó atrás una economía rural y de manufacturas tradicionales (manuales) para dejar paso a la gran industria mecanizada. Este avance supuso no sólo una revolución en la economía, sino que produjo importantes transformaciones sociales; tuvo lugar un desarrollo tecnológico considerable, pero originó, entre otros aspectos, consecuencias sociales negativas. Dado que el proceso de industrialización tuvo su mayor repercusión en las grandes urbes -por un lado, debido al establecimiento de las grandes industrias y, por otro, por la menor necesidad de mano de obra en el sector de la agricultura y ganadería-, provocó un éxodo rural y crecimiento demográfico hacia éstas que favoreció la aparición de altas tasas de desempleo y bajos niveles salariales, repercutiendo significativamente en las grandes masas poblacionales (Audigier, 2014).

A lo anterior hay que añadir que, en el ámbito económico, las transformaciones que se produjeron en el siglo XIX intensificaron la competencia económica (Chanial y Laville, 2001). Por otro lado, este siglo se caracterizó por un conflicto permanente entre el Estado y la sociedad civil (Draperi, 2014), generando un contexto propicio para el surgimiento de movimientos sociales en general y del cooperativismo en particular.

Así, esta época marcada por la falta de ética social ante un capitalismo de filosofías liberales, desencadenó todo un proceso de críticas y cuestionamientos del sistema socioeconómico desde diferentes movimientos de pensamiento de carácter multidisciplinar, es decir, desde distintas disciplinas e ideologías. Estos movimientos abarcaron diferentes ámbitos y países, diversos contextos, que tuvieron como eje central los acontecimientos en torno a la Revolución Industrial. En esta línea, destacaron como protagonistas de estos sucesos principalmente los territorios de Francia y Gran Bretaña, donde estuvieron representados estos movimientos por los socialistas utópicos como los franceses Charles Fourier (1772-1837) y Henri de SaintSimon (1760-1825) o el británico Robert Owen (1771-1858).

En línea con lo anterior, hay que destacar que, a pesar de la existencia de otras actuaciones institucionales como la Declaración de los Derechos de 1789 y otras iniciativas para democratizar la sociedad en Francia, éstas no fueron suficientes para frenar las miserias sociales y las explotaciones obreras (Chanial y Laville, 2001), siendo esto lo que llevó a diversos autores del pensamiento económico y social de la época a cuestionarse este sistema.

Uno de los pensadores de la época que se embarcó en esta crítica del sistema fue Charles Fourier (17721837). Este socialista utópico francés, de familia acaudalada pero que vivió como humilde trabajador del comercio, fue consciente de los problemas que atravesaba la sociedad de la época. Estaba convencido de que estas dificultades eran fruto de las inadecuadas estructuras sociales y de la inexistencia de oportunidades de participar en la producción y el beneficio empresarial por parte de los trabajadores más humildes (Divar, 2011).

Una de las posibles soluciones que Fourier planteaba para paliar esta deficiencia en la estructura social era la organización de los trabajadores en falansterios que consistían en comunidades o agrupamientos familiares, al objeto de ser autosuficientes, como base para la transformación social, trabajando cada individuo según sus capacidades y gustos y sin la existencia de propiedades privadas. Los ingresos que se obtuviesen de este agrupamiento serían compartidos entre sus miembros en función de la aportación (trabajo y capital) de cada uno. Se trataba de una vida en comunidad -con completos equipamientos como bibliotecas, guarderías, etc.- ya que, según Fourier, proporcionaría ventajas como realizar demandas de productos y servicios en masa (vivienda, alimentación, enseñanza, etc.) de forma colectiva, repercutiendo en su menor coste. De esta forma, estableció la idea principal de la cooperativa de consumidores ${ }^{5}$ (Audigier 2014). Sin embargo, a pesar de sus esfuerzos por intentar atraer a capitalistas para financiar a estas comunidades mediante aportaciones voluntarias -pues se mostraba partidario de la remuneración de capitales financiadores- no tuvo éxito y el falansterio pasó a ser considerado una alternativa utópica (Cole, 1964; Divar, 2011, Audigier, 2014).

También hizo referencia a otras cuestiones como la necesidad de reorganizar la forma de trabajar y eliminar el trabajo monótono, alternando el tiempo con descanso y formación para incrementar los rendimientos (Audigier, 2014). 
Continuando con el socialismo utópico y el debate sobre la propiedad de los medios de producción, destacó también Henri de Saint-Simon (1760-1825), filósofo y economista francés que sentó escuela defendiendo la planificación estatal para aumentar la producción económica (Landreth y Colander, 2006), con una propiedad de los medios de producción colectiva bajo el control estatal, planteando así un socialismo de Estado. Tuvo tal influencia que dio lugar a la doctrina saint-simoniana, defensora de la eliminación de las plusvalías de producción en favor de las rentas del trabajo producidas por el trabajo asociado (Divar, 2011).

Saint-Simon estaba convencido de que, en un contexto con graves problemas sociales, el hecho económico se anteponía al derecho político (Chanial y Laville, 2001). A partir de estas ideas, comenzaron a germinarse lo que más tarde serían consideradas cooperativas de trabajo asociado o de producción, siendo Philippe Buchez (1796-1865), discípulo saint-simoniano, y Louis Blanc (1812-1882) sus precursores más significativos (Divar, 2011).

Por otro lado, Buchez, junto a Fréderic Le Play (1806-1882), desde el cristianismo humanista (o cristianismo social) en general, además de tener en cuenta a las cooperativas como herramientas para mejorar las condiciones laborales de los trabajadores obreros y hacerse con la propiedad de los medios de producción, veían en éstas la oportunidad de frenar la cada vez mayor influencia de marxistas y anarquistas en la sociedad que promulgaban ideas sobre el ateísmo (García, Via y Xirinacs, 2006).

Las ideas de los saint-simonianos y las de los fouristas encontraron un punto de convergencia en la concepción de que eran necesarias nuevas organizaciones sociales, basadas en el asociacionismo, que dieran respuestas a los problemas de carácter multidimensional del momento -sociales, económicos y morales-. En este sentido, para Saint-Simon, la asociación estaba en el centro de todo proyecto de cambio social en busca de la armonía, siendo la reforma económica y social sólo una parte de este proyecto general de cambio de mayor complejidad (Chanial y Laville, 2001).

Sin embargo, a pesar de esta idea convergente, existieron diferencias considerables entre ambas corrientes: los saint-simonianos, apoyados en la religión como una forma asociativa, la consideraban como un instrumento de unión para reforzar los vínculos sociales, generando relaciones de afecto entre las personas que la conforman, en contra del aislamiento o egoísmo individualista. Entre sus propuestas estaban la eliminación de la ley de la oferta y la demanda, de la venta y de la compra, de la herencia o la transformación de la propiedad para focalizarla hacia actividades sociales. El Estado, que estaría representado por la asociación de trabajadores, adquiriría un papel esencial en la redistribución de la riqueza, en lo que se refiere a créditos o factores de producción, que canalizaría hacia los mejores trabajadores (Chanial y Laville, 2001; Divar, 2011).

Fourier cuestionó estas ideas de los saint-simonianos calificándolos de autoritarios y moralistas ya que, según él, lo que lleva a asociarse a los hombres son los gustos, sentimientos o ideas comunes con el objeto de ayuda mutua y su emancipación completa, en lugar de afinidades de carácter religioso. De la suma de todas estas asociaciones surgidas a partir de las características comunes del grupo, derivaría el equilibrio, la estabilidad o la armonía universal o global, es decir, el estado supremo del desarrollo humano. Es por ello que planteó la creación de falansterios a todos los segmentos sociales, de diferentes edades y sexo, para la organización tanto de la producción como del consumo (Chanial y Laville, 2001). A diferencia de la corriente saint-simoniana, los fouristas contemplaban el criterio de la libre asociación. Finalmente, tanto las formas de asociación de los saint-simonianos como de los fouristas, fracasaron (Audigier, 2014).

En lo que respecta al socialismo y cooperativismo inglés, su fundador fue Robert Owen (1771-1858), empresario industrial que siguió los ideales de Godwin sobre la creencia en la habilidad del ser humano para mejorar las situaciones desfavorables y en el planteamiento de que son los factores institucionales los que ocasionan estos males. Owen, a pesar de creer en la necesidad de sustituir el proceso de mercado competitivo por el de cooperativas, no prestó atención al concepto de conflicto de clases defendido desde otras escuelas de pensamiento (Landreth y Colander, 2006).

Este representante del socialismo inglés, discípulo de Saint-Simon, puede ser considerado la figura principal a partir de la cual empieza a surgir la doctrina cooperativa moderna. Sus ideas se desarrollaron desde su propia experiencia: propietario de una fábrica textil, mejoró las condiciones de vida de sus trabajadores y entornos mediante medidas como la reducción de la jornada de trabajo o creación de escuelas para los hijos de sus empleados (Merino, 2005). De manera general, puede sostenerse que sus ideales destacaban por defender la comunidad de bienes, el trabajo colectivo y la distribución equitativa del producto (Quijano y Reyes, 2006).

Por otro lado, el movimiento cooperativo también estuvo representado previamente por el cuaquerismo: Owen y Fourier recibieron influencias de Plockboy (1620-1700), cuáquero, considerado como uno de los principales defensores y pionero de una economía alternativa humanista y solidaria. Plockboy propuso un cooperativismo para paliar los problemas de los más pobres y evitar su miseria y así constó en 1659, en un panfleto que publicó denominado "Ensayo sobre un proceso que les haga felices a los pobres de esta nación y a los de otros pueblos, consistiendo en reunir cierto número de hombres competentes en reducida asociación económica, o pequeña república, en la cual cada uno conserve su propiedad y pueda, sin 
necesidad de acudir a la fuerza, ser empleado en la categoría de trabajo para la cual tenga más capacidad" (Divar, 2010: 147).

Cuadro. 1. Principales precursores del cooperativismo en Europa (siglo XIX)

\begin{tabular}{|c|c|}
\hline Autor & Pensamiento, ideas y principales contribuciones \\
\hline $\begin{array}{l}\text { P.C. Plockboy }(1620-1700) \text {, } \\
\text { Gran Bretaña }\end{array}$ & $\begin{array}{l}\text { Cuáquero. Pequeñas repúblicas cooperativas para acabar con las miserias de los más } \\
\text { pobres. }\end{array}$ \\
\hline $\begin{array}{l}\text { J. Bellers (1654-1725), } \\
\text { Gran Bretaña }\end{array}$ & $\begin{array}{l}\text { Cuáquero. Asociación de los pobres mediante colonias integrales de trabajo } \\
\text { colectivo (combinación de trabajo agrícola e industrial). }\end{array}$ \\
\hline C. Fourier (1772-1837), Francia & $\begin{array}{l}\text { Existencia de inadecuadas estructuras sociales. Organización de la sociedad en } \\
\text { falansterios. Sentó las bases de las cooperativas de consumidores. }\end{array}$ \\
\hline $\begin{array}{l}\text { H. Saint-Simon (1760-1828), } \\
\text { Francia }\end{array}$ & Planificación estatal, socialismo de Estado (medios de producción colectivizados). \\
\hline $\begin{array}{l}\text { R. Owen (1771-1858), } \\
\text { Gran Bretaña }\end{array}$ & $\begin{array}{l}\text { Las condiciones desfavorables de la sociedad se deben a los factores institucionales. } \\
\text { Sustitución del sistema de mercado competitivo por el de las cooperativas } \\
\text { (rechazando el conflicto de clases). Cooperativas integrales. }\end{array}$ \\
\hline $\begin{array}{l}\text { W. King (1786-1865), } \\
\text { Gran Bretaña }\end{array}$ & $\begin{array}{l}\text { Desarrollo de las ideas de Owen en el periódico The Co-operator. Solución para la } \\
\text { emancipación de los pobres: la ayuda mutua. Cooperativas de consumo. }\end{array}$ \\
\hline P. Buchez (1796-1865), Francia & $\begin{array}{l}\text { Corriente saint-simoniana, socialismo cristiano. Preocupación por la influencia } \\
\text { creciente de marxistas y anarquistas. Cooperativas como medio de lucha contra las } \\
\text { malas condiciones de la clase obrera: cooperativas de trabajo asociado para } \\
\text { producir. }\end{array}$ \\
\hline L. Blanc (1811-1882), Francia & $\begin{array}{l}\text { Emancipación de la clase obrera mediante talleres de trabajo asociado. Cooperativas } \\
\text { de producción industrial. }\end{array}$ \\
\hline $\begin{array}{l}\text { H. Schulze-Delitzsch (1808- } \\
\text { 1883), } \\
\text { Alemania }\end{array}$ & $\begin{array}{l}\text { Búsqueda de la mejora de la clase media urbana. Defensor del colectivismo para } \\
\text { solventar los inconvenientes del sistema capitalista, pero sin renunciar a este } \\
\text { sistema. Cooperativas de crédito. }\end{array}$ \\
\hline $\begin{array}{l}\text { F. Wilhelm Raiffeisen (1818- } \\
\text { 1888), } \\
\text { Alemania }\end{array}$ & $\begin{array}{l}\text { Desde el cristianismo y humanismo, defensor de los más desfavorecidos. } \\
\text { Cooperativas de crédito rurales. }\end{array}$ \\
\hline $\begin{array}{c}\text { Wilhelm Haas (1839-1913), } \\
\text { Alemania }\end{array}$ & $\begin{array}{l}\text { Desde un enfoque más práctico o económico que dogmático, cooperación basada en } \\
\text { la ayuda mutua. Cooperativas en el sector agropecuario: de consumo, de crédito, de } \\
\text { producción, etc. }\end{array}$ \\
\hline
\end{tabular}

Fuente: Elaboración propia a partir de Divar (2010, 2011), Monzón (2003), Landreth y Colander (2006), Quijano y Reyes (2006) y Gaminde (2017).

En esta búsqueda de soluciones para los pobres, desde el cuaquerismo, destacó también J. Bellers (1654$1725)^{6}$. Estas soluciones estaban apoyadas en el asociacionismo mediante colonias para la combinación de trabajo agrícola e industrial, evitando así intermediarios en el proceso productivo y la explotación excesiva de la mano de obra (Quijano y Reyes, 2006).

Siguiendo a Merino (2005), las aportaciones de estos dos autores cuáqueros se pueden identificar y concentrar en las ideas de ayuda mutua, integración de las funciones económicas mediante una estructura democrática y eliminación de intermediaros en los procesos económicos. 
Retomando las ideas de Owen, a conclusiones similares a las de este autor llegaron los socialistas ricardianos como Thomas Hodgskin (1773-1869), John Gray (1799-1833) o, su máximo exponente, William Thompson (1775-1833), quien presentó el cooperativismo como un sistema alternativo al capitalista con una importante acción de los sindicatos. Recibieron tal denominación por aplicar la teoría del valor trabajo de David Ricardo $(1817)^{7}$ acerca de que los propietarios de la tierra o terratenientes no aportaban realmente valor alguno y, por ello, eran considerados parásitos del sistema al recibir un dividendo social sin realizar una verdadera función económica imprescindible (Monzón, 2003; Landreth y Colander, 2006).

Pero el movimiento asociacionista también estuvo presente en el anarquismo y el marxismo. Desde el anarquismo en general y el mutualismo en particular, Pierre-Joseph Proudhon (1809-1865) sostuvo que la sociedad debía basarse en este último, ya que se adapta mejor a la idea que tiene de rechazar toda autoridad y de la búsqueda de una sociedad en la que haya reciprocidad entre iguales, haciendo, de esta manera, una diferencia con el concepto de solidaridad relacionada con el altruismo y la caridad (Quijano y Reyes, 2006).

Desde el marxismo, con Karl Marx (1818-1883) como máximo exponente de lo que se denominó socialismo científico, el cooperativismo fue considerado como transformador de una sociedad capitalista a una socialista (Monzón, 2003). Analizó el papel que ocuparían las cooperativas en el sistema económico a partir de la identificación de los diferentes actores según el lugar que ocupasen, "dominados o dominantes", teniendo lugar la transformación cuando las reglas de funcionamiento del sistema, la de los dominantes, cambian. De otra forma, el cambio se daría cuando la plusvalía de la actividad económica pasara a manos de los responsables de generarla, los trabajadores (o dominados en este caso). Para ello, el trabajo asalariado debía convertirse en trabajo asociado, poniendo en común el trabajo y los medios de producción y siendo el proletariado el que pasase a tomar el control de la organización. Por tanto, Marx proponía un cooperativismo de trabajo asociado dejando al margen otras actividades de carácter asociacionista como el consumo, los seguros o las viviendas (Alonso, 1999).

Hay que señalar que la principal diferencia respecto a los socialistas utópicos es que Marx sí contemplaba un movimiento revolucionario obrero: los socialistas utópicos defendían, mediante discusiones constantes entre ellos, un cambio o transformación social de manera pacífica a partir de la propia realidad que estaban viviendo, mientras que para Marx era necesario una lucha de clases ante el dominio progresivo de la empresa capitalista (Draperi, 2014).

El movimiento asociacionista en general y cooperativo en particular adquirió, por tanto, especial interés desde las diferentes posturas socialistas en sentido amplio (socialismo utópico, cristianismo humanista, socialismo ricardiano, anarquismo o marxismo), considerando que es, desde esta ideología, cuando surgen los primeros movimientos. No obstante, también despertó interés en otras corrientes de pensamiento como la de los economistas neoclásicos.

En línea con lo anterior, desde el pensamiento neoclásico, en la escuela liberal destacó el francés Leon Walras (1834-1910) para quien la función de las sociedades cooperativas en el sistema capitalista consistía en complementarlo pero no en sustituirlo. Para Walras, el asociacionismo de los trabajadores en cooperativas permite a éstos adaptarse al funcionamiento del mercado, aunque desde el ámbito de la producción más que desde el de la distribución, siendo esta asociación una manifestación de la libertad económica del capitalismo (Monzón, 2003; García, Via y Xirinacs, 2006). Lo realmente relevante es conseguir un mundo menos capitalista y dotado de mayor moral mediante la introducción de la democracia en el ámbito de la producción (Walras, $1898^{8}$ ).

Desde una perspectiva más científica, este autor -Walras-, matemático, identificó, por un lado, una economía como ciencia pura, que es la que funciona mediante el sistema y mecanismos del mercado y que puede expresarse a través de formulaciones matemáticas; y, por otro, una parte de la economía vinculada a lo social, la ES, y que tiene como función corregir a la anterior, a la economía pura. Es decir, para Walras la ES depende de una economía natural, la de mercado, y es una disciplina de la misma (Chanial y Laville, 2001). A todo ello hay que sumar la defensa del asociacionismo en el trabajo para superar las malas condiciones laborales del proletariado que fue defendido en Inglaterra, también desde la escuela liberal, por John Stuart Mill (1806-1873) (Defourny, 1992).

Toda esta diversidad de ideas lleva a la dificultad de establecer realmente los orígenes del cooperativismo según el pensamiento ideológico (Divar, 2011) pero que, a pesar de sus diferentes tendencias, presenta un núcleo común: una reacción, bien sea pacífica o revolucionaria, ante las circunstancias socioeconómicas del momento.

Cabe destacar aquí un matiz: a menudo, se suelen plantear similitudes entre socialismo, cooperativismo y sindicalismo dado su surgimiento a partir de los movimientos obreros que aparecieron en un mismo contexto (Cuadro 2). Sin embargo, como sostiene el profesor Laserre (1972), aunque el cooperativismo nació en similares contextos o circunstancias que el sindicalismo y el socialismo -impulsados por las miserias sociales de la época se prestó atención a la acción colectiva para paliar estas desfavorables condiciones de vida-,

Cuya obra se titula "Principios de economía política y tributación".

Citado por Monzón (2003). 
existen diferencias significativas entre los tres movimientos sociales: el cooperativismo estaba centrado en el modelo empresarial gestionado por los propios trabajadores, entre otras cuestiones para acabar con la explotación del proletariado; el sindicalismo era de carácter reivindicativo y se situaba al margen de la gestión interna de la empresa, es decir, no formaba parte de la toma de decisiones que se daban en el órgano empresarial; lo mismo ocurre también en el socialismo político donde los trabajadores no tenían participación de forma activa en la gestión empresarial, sino que practicaban los progresos sociales realizados "desde arriba" o desde un ámbito más extenso como puede ser el Estado (Laserre, 1972). Pero todos estos movimientos contemplaron el asociacionismo como instrumento clave de respuesta a los problemas de carácter social y económico del momento.

Cuadro. 2. Reacciones de la clase obrera ante la producción industrial mecanizada

Destructores de máquinas
Partidos políticos obrero-populares (laboristas)
Sindicalismo
Socialismo $\begin{aligned} & \text { De Estado } \\ & \text { Pequeño-burgués } \\ & \text { Democrático } \\ & \text { Cristiano } \\ & \text { Utópico } \\ & \text { Científico }\end{aligned}$
Solidarismo
Anarquismo
Humanismo
Cooperativismo
Mutualismo

Fuente: Quijano y Reyes (2006).

Aunque en cierta forma las ideologías descritas tenían determinado carácter utópico por los ideales que defendían, lo cierto es que sí tuvieron lugar prácticas asociativas para ponerlos en marcha. Entre éstas se encuentra la cooperativa de consumo de los Pioneros de Rochdale, creada en 1844 que, siguiendo las ideas de Owen, ha sido la de mayor influencia en el movimiento cooperativo moderno. Además, en la década de 1840 , las asociaciones fueron un prolongamiento del gremio en el que patrones y obreros pusieron en común su trabajo mediante criterios de solidaridad, con el objetivo de sobrevivir a la gran industria mediante actividades de producción, mutuales, acciones sindicales y cooperativas (Draperi, 2014), ejemplo de que este movimiento asociativo respondió a intereses muy variados.

Por otro lado, no debe olvidarse que, además de su impulso en territorios como Francia y Gran Bretaña, desde Alemania el movimiento cooperativo también tuvo su envite con los políticos Schulze-Delitzsch (1808-1883), Wilhelm Raiffeisen (1818-1888) y Wilhelm Haas (1839-1913).

Schulze-Delitzsch fue el creador de las cooperativas de crédito. Motivado por el hecho de que el sistema capitalista presentaba una serie de dificultades para la clase media urbana, defendió la cooperación y la ayuda mutua para solventarlas entre los artesanos de la época, pero sin renunciar a dicho sistema. Wilhelm Raiffeisen siguió sus pasos; desde una posición cristiana y humanista, promovió activamente la creación de cooperativas de crédito rurales para los más desfavorecidos. Esta posición religiosa de Wilhelm Raiffeisen provocó una reacción de Wilhelm Haas, quien consideraba, dicha posición, excesivamente dogmática. Haas, desde un enfoque más práctico, se centró en el sector agropecuario contemplando la actividad cooperativista de manera integral (cooperativas de crédito, de consumo, de producción, etc.) (Gaminde, 2017).

A partir de lo anterior, se puede sostener que el cooperativismo y los movimientos asociativos en general del siglo XIX, fueron defendidos, tanto en las ideas como en las prácticas, por intereses muy variados y diferentes movimientos como el anarquismo, el socialismo o el sindicalismo. Se pusieron en marcha prácticas asociativas al mismo tiempo que se buscaba una construcción de un marco teórico con matices ideológicos. Todo ello tiene el valor añadido de que se produjo, además, en un contexto en el que las constantes discusiones en el pensamiento económico sobre las relaciones entre la economía, la política, la moral y la religión eran habituales (Chaves, 1999).

Por tanto, entre las diferentes escuelas y tendencias del movimiento asociacionista y cooperativo, tanto desde el pensamiento económico como desde las prácticas, no existió una corriente común en cuanto a la función que debía desempeñar éste, resultado de los diversos contextos políticos y culturales. Por ello, en la actualidad, aunque no existe un consenso generalizado sobre el concepto de ES, sí existe en cuanto a su 
origen como fruto del conjunto de todas estas corrientes -de pensamiento y de prácticas- de la Europa del siglo XIX (Defourny, 1992).

\section{Francia en el epicentro del nacimiento de la ES: un marco teórico de referencia}

Como se ha señalado en el apartado anterior, la ES surge de manera importante en Francia, pero no por casualidad: su nacimiento se produjo a finales del siglo XVIII con las revoluciones de 1789 y con la influencia de filósofos como Rousseau que basaron sus ideas en el pueblo soberano y en el conocido lema de "Liberté, égalité, fraternité". La ES constituye así una herramienta portadora de estos principios en el ámbito económico que trascienden al ámbito político (Draperi, 2011).

El término de ES apareció por primera vez en el año 1830 con Charles Dunoyer en su obra "Traité d'économie sociale" en la que se defendía la necesidad de adoptar un enfoque moral de la economía. Además, en el periodo 1820-1860 tuvo lugar una corriente de economistas sociales bajo la influencia de Thomas R. Malthus y de Simonde de Sismondi, defensores de que la verdadera cuestión central de la economía es el hombre y no la riqueza en sí misma. Se desarrolló, por parte de estos economistas sociales, un enfoque teórico de lo social en la búsqueda de un nexo entre la economía y la moral pero sin plantear un marco teórico concreto para la ES (Monzón y Chaves, 2012).

Aunque otros autores como León Walras o Fréderic Le Play también realizaron estudios sobre la ES, como se ha señalado anteriormente, es Charles Gide (1847-1932) quien verdaderamente comenzó a proponer un marco teórico de referencia para la ES concediéndole un lugar destacado en el sistema económico.

Este economista francés, miembro de la Escuela de Nîmes -que entre otras cuestiones defendía los valores de ayuda mutua y la educación económica mediante la cooperación- y con pensamiento liberal pero espíritu solidarista, emprendió el camino en el movimiento cooperativo en Francia en los años 1860-1870. A diferencia de las anteriores ideas socialistas que proponían la cooperación en la producción, esta escuela lo hacía desde el consumo (Defourny, 1992; Pénin, 1997). En 1880, Gide empezó a relacionarse con la liberal Sociedad de Economía Política de París, con diferencias respecto a las ideas de economistas que representaron la vanguardia de cierta heterodoxia del momento como Paul Cawés y León Walras -quien había tratado también el concepto de ES-, a los que llegó a calificar de más ortodoxos que incluso la corriente dominante liberal (Breton, 2000); Gide no creía en el orden natural del liberalismo económico que pivotaba en torno a las leyes de oferta y demanda (Gide, $\left.2000^{9}\right)$.

Sus principales críticas a las escuelas de pensamiento han sido plasmadas, entre otras obras, en Principes d'économie politique (1883). Para Gide el capitalismo no es un mal en sí mismo. Éste existió desde mucho antes de la Revolución Industrial pero, a partir de la misma, su uso y fin cambió: antes estaba al servicio del hombre (a través del pastoreo o la agricultura primitiva), pero se ha desvinculado totalmente de las manos de los trabajadores y es por ello que comienzan a establecerse conjeturas alrededor del mismo, sobre todo desde las corrientes socialistas (Gide, 2000).

Según Gide (2000), hay tres formas de emplear el capital: la primera, la del trabajador independiente, propietario de sus medios e instrumentos para aumentar la productividad de su trabajo; la segunda, la del capital aportado por el empresario para proveer de recursos necesarios a los trabajadores asalariados para producir, recibiendo posteriormente parte del producto y del beneficio fruto del trabajo colectivo; y la tercera, la forma capitalista-rentista en la que la persona que aporta el capital no tiene relación directa alguna con la organización, limitándose a recibir un interés o dividendo previamente acordado bajo las formas de obligaciones o acciones.

Así, Gide planteó que se ha producido un cambio desde la Revolución Industrial en cuanto a la concepción del capital y al lugar que ocupa en las prácticas y pensamientos de la corriente liberal: anteriormente a este fenómeno, el capital era contemplado un bien en sí mismo; sin embargo, a partir de entonces, su concepción varía considerándose como un factor clave en los procesos de producción determinante del crecimiento económico. Un cambio de percepción sobre el capital que, además, estuvo muy marcado desde el socialismo científico a partir de la obra de El Capital de Karl Marx (Gide, 2000) y que fue criticado por este economista francés.

Aunque Gide compartía con otras corrientes socialistas las injusticias del sistema económico, esto no le privó de realizar ciertas críticas a las ideas que defendían los impulsores del socialismo científico. Entre estas críticas figuraba la inexistencia de un verdadero plan para una sociedad futura y que se limitaba a aceptar el marco del capitalismo de la época dado que, simplemente, se centraba en reemplazar a los expoliadores por los expoliados (Gide 1955: 28), y de ahí que el instrumento para ello fuese la lucha de clases. Según Gide (1955), la escuela socialista no logró su principal objetivo que consistía en cambiar el sistema económico.

9 Vigesimosexta edición de la obra llamada Principes d'économie politique, escrita en 1883. 
En 1889, Gide, en su programa de cooperación económica, planteó la posibilidad de la unión de todas las cooperativas de consumo, desvinculándose de las corrientes económicas predominantes de entonces (clásicos y marxistas), siguiendo tres etapas: la primera consistía en la unión de sociedades para construir almacenes y realizar compras a gran escala; la segunda etapa se centraba en utilizar los beneficios logrados en la primera para fabricar todo lo que necesitase la sociedad; y la tercera y última, establecía que con el paso del tiempo y dado los beneficios obtenidos de las dos anteriores, puedan adquirir las tierras agrícolas y granjas para producir, de manera directa, bienes de primera necesidad (Martínez, 2013). De esta manera, lo que Gide propuso fue que las cooperativas se desarrollaran progresivamente y asumiendo toda la cadena de producción.

Este asociacionismo cooperativista era indispensable para conseguir la independencia de los explotados consumidores sujetos a los intereses egoístas de los productores, constituyendo así un nuevo sistema económico y social más justo, basado en el establecimiento de un precio justo en los sistemas de intercambio, todo ello de manera pacífica. Gide acabó interpretando su proposición como una república cooperativa (Quijano y Reyes, 2006). Anteriormente, Plockboy ya había hecho alusión a la necesidad de una república cooperativa, pero a diferencia de Gide, lo hizo desde el cooperativismo de producción.

En línea con lo anterior, con el concepto de emancipación de la clase obrera a partir de sus propios medios como clave de lo que debiera ser el nuevo sistema económico, Gide defendió una sociedad desde la federación de pequeñas cooperativas locales de consumo para lograr la transformación social de manera gradual hasta alcanzar la república cooperativa mediante las tres etapas mencionadas -la primera con la conquista del comercio, la segunda de la industria y, finalmente, de la agricultura- (Monzón, 2003). Así, dejando de lado a la intervención del Estado y a las instituciones capitalistas tradicionales, propuso un nuevo sistema social y económico. Además, como defensor de la escuela solidarista, veía en este asociacionismo cooperativo la máxima expresión del concepto de solidaridad, ya que los miembros asociados renuncian a una parte de los dividendos para destinarlos a acciones de utilidad general (Gide, $1924^{10}$ ). Por tanto, los conceptos de emancipación, precio justo, solidaridad y utilidad general fueron clave para justificar y proponer un sistema socioeconómico, mediante el cooperativismo de consumo, que constituyese una verdadera obra de transformación social. Por ello, Gide definió a las organizaciones de ES como las verdaderas instituciones del progreso social basadas en una economía moral (Demoustier, 2006) estableciendo así, a partir de la misma, una nueva economía política (Alonso, 1999).

Sus ideas tuvieron influencia y fueron continuadas por otro economista francés, Bernard Lavergne (18841975), quien en 1926 comenzó a difundir las obras de Charles Gide en la revista de la que era director: Revue des études coopératives (REC). A las ideas de ambos defensores de las organizaciones de ES, particularmente desde el cooperativismo de consumo, se unieron posteriormente otros pensadores como George Fauquet (1873-1953), Henri Desroche (1914-1994) o Claude Vienney (1929-2001), para quienes las teorías cooperativas se definían a partir de la economía clásica y la socioeconomía crítica (Draperi, 2011), a diferencia de Gide quien no llegó a realizar un análisis crítico general de toda la economía capitalista (Monzón, 2003).

Las obras de Desroche y Vienney han destacado por sus diferencias y, a su vez, complementariedad. Henri Desroche, sacerdote y sociólogo, recibió especial influencia de Gide. Planteó su teoría a partir del cristianismo y el marxismo, argumentando que el primero no cuenta con la capacidad suficiente para cambiar el orden social y, por ello, debía apoyarse en el marxismo para la acción social y humanista (Draperi, 2011). Escribió obras como "Le Projet coopératif. Son utopie et sa pratique, Ses appareils et ses réseaux. Ses espérances et ses déconvenue" o "Pour un traité d'économie sociale", publicadas en 1976 y 1983 respectivamente.

Una de las aportaciones más interesantes de Henri Desroche (1976: 337) ha sido el "cuadrilátero de actores" (quadrilatère des acteurs): se trata de las relaciones complejas entre cuatro agentes fundamentales de la organización de poder en la estructura de una entidad de ES. Estos agentes son los socios, administradores, gerentes y empleados, dando lugar así a una democracia cuatripartita y manteniendo el equilibrio dentro de la organización (Gráfico 1). 
Gráfico. 1. El cuadrilátero de actores de la empresa de Economía Social

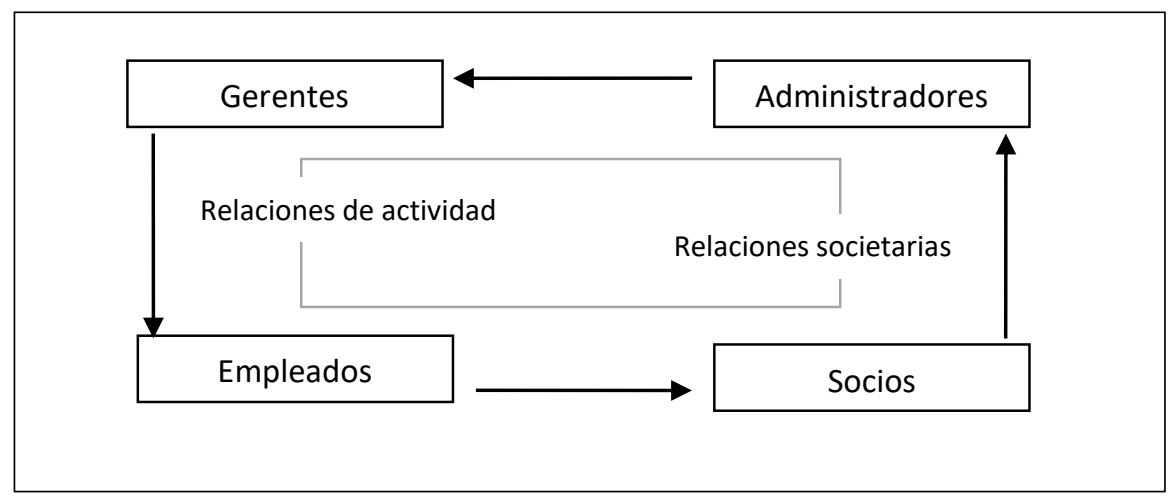

Fuente: Desroche (1983)

No obstante, Desroche argumentó que puede ocurrir que este equilibrio se quiebre o simplemente que sea inexistente por conflictos relacionales entre los miembros. Para evitar estos problemas y mantener el equilibrio relacional, Desroche sostuvo la necesidad de contar con un estatuto jurídico que regule, mediante reglas específicas, las relaciones entre los miembros de la organización. Es a partir de la definición de estos estatutos jurídicos, para mantener el citado equilibrio relacional, cuando se da forma a la organización de ES. Los estatutos más frecuentemente utilizados han dado lugar, en un primer momento, a cooperativas, mutuas y asociaciones. No obstante, aunque ésta es una primera aproximación a la definición de ES, las prácticas de estas organizaciones no garantizan el cumplimiento de las reglas a través de los estatutos jurídicos, pudiendo ocurrir que existan otras organizaciones que muestren esta misma complejidad relacional sin ser cooperativas, asociaciones o mutuas. Para solventar esto, Desroche (1983) añadió el concepto de "componentes inciertos" dando cabida a empresas comunitarias, sindicales, municipales y públicas que funcionaran bajo criterios democráticos dentro de la ES, combinando así entidades del mercado y del sector público (Desroche, 1976, 1983; Lévesque y Mendell, 2005) (Gráfico 2).

Por su parte, Claude Vienney $(1980,1982)$ se inspiró en el análisis de George Fauquet (1935) sobre la cooperación, entendida ésta como el agrupamiento de personas en una empresa con relaciones recíprocas y unidas por la doble cualidad de relación de asociación y de actividad (como socios y trabajadores) (Demoustier, 2002). Además, para Vienney, al igual que para su predecesor, las cooperativas funcionan en la economía de mercado atribuyéndole un doble papel: como agente de adaptación al funcionamiento y a las reglas de la economía de mercado y como agente de transformación de los miembros que la conforman para otorgarles poder empresarial de forma colectiva (Malo, 2003). Este autor realizó sus trabajos sobre cooperativismo mediante una lectura crítica a las teorías neoclásica y marxista, a diferencia de Desroche que se apoyó en el marxismo. Según Vienney, la teoría neoclásica solo centraba su interés en demostrar que eran empresas que se ajustan -sus formas y sus reglas- al funcionamiento del sistema capitalista y, por tanto, no explicaba las transformaciones socioeconómicas de las que derivan (Draperi, 2002). 
Gráfico. 2. Los componentes ciertos e inciertos de la Economía Social

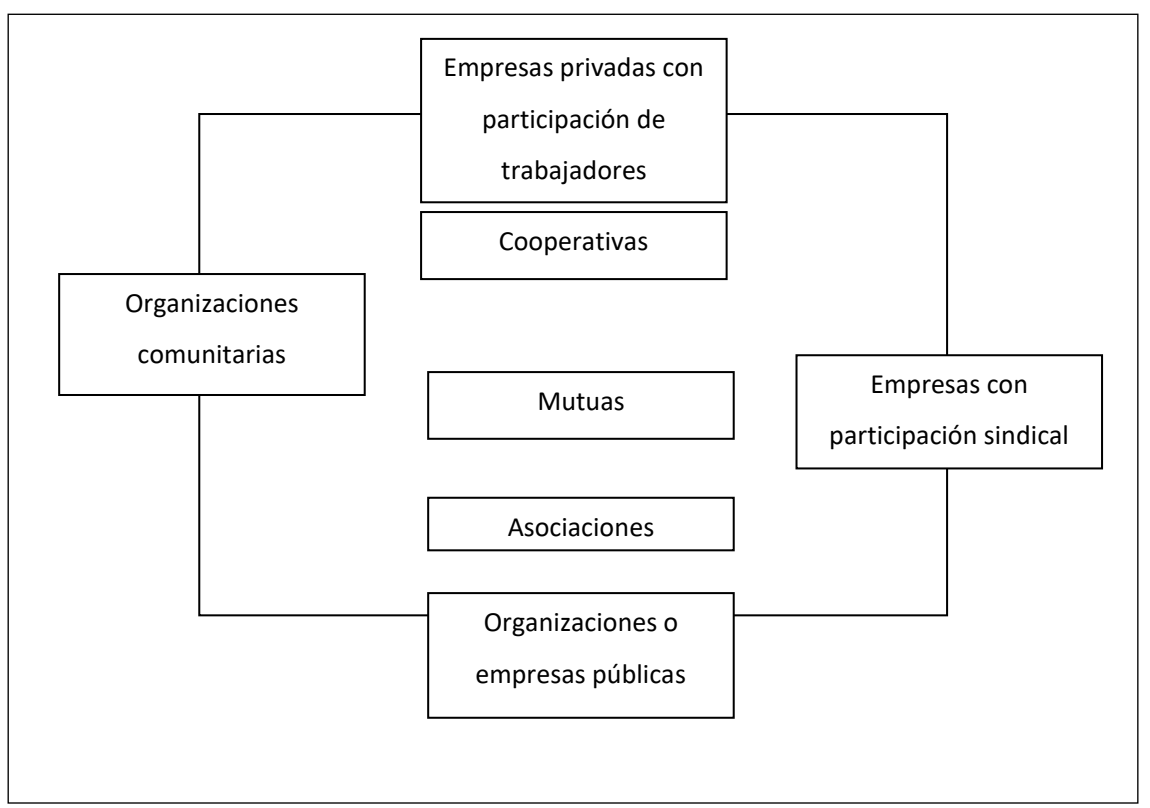

Fuente: Lévesque et Mendell (2005).

Estos argumentos de Vienney se justifican por el contexto en el que vivió: la crisis de los 70 estaba requiriendo una reorganización o reestructuración empresarial, por los elevados costes de producción y altas tasas de desempleo ${ }^{11}$, por lo que sus estudios se centraron en la búsqueda de una teoría explicativa sobre las especificidades, formaciones y transformaciones de las cooperativas (Demoustier, 2002; Moreau, 2002). Para este economista había dos aspectos importantes a considerar: la necesidad y la posibilidad de reconstruir la actividad mediante la movilización de recursos autónomos, más que del acceso al poder. Puso el acento en la movilización de actores para acceder a los recursos, para reorganizarse, teniendo en cuenta el entorno y la adaptación de estas organizaciones al mismo (Demoustier, 2002). De esta forma, se centró en el funcionamiento de las cooperativas y las consideró como un grupo de personas que se asocian con el objeto de poner en común los medios necesarios para desarrollar su actividad profesional y consolidar su subsistencia (Vienney, 1980).

Desroche, a diferencia de Vienney que hizo sus estudios desde el campo económico, trató la disciplina cooperativa desde el ámbito de la sociología, pero, como sostiene Draperi (2002), es difícil contemplar a uno sin evocar al otro, pues ambos tuvieron una importante influencia en el pensamiento cooperativo francés en la segunda mitad del siglo XX. Es decir, se puede sostener que estas obras más que oponerse se complementan (Malo, 2003) (Cuadro 3).

Cuadro. 3. La complementariedad de las obras de Henri Desroche y Claude Vienney

\begin{tabular}{|c|c|c|}
\hline \multirow{2}{*}{ Disciplina de referencia } & Henri Desroche & Claude Vienney \\
\hline Objeto de estudio & Sociología & Economía \\
\hline Periodo & $\begin{array}{c}\text { El proyecto cooperativo. Las utopías } \\
\text { alternativas }\end{array}$ & $\begin{array}{c}\text { La organización cooperativa. } \\
\text { Transformación de las organizaciones }\end{array}$ \\
\hline Sociedad observada & Siglo XIX a segunda mitad del siglo XX & Segunda mitad del siglo XX \\
\hline Contexto & Europa con perspectiva mundial & Francia \\
\hline & $\begin{array}{c}\text { Obtención de la independencia y } \\
\text { desarrollo de los países del sur }\end{array}$ & $\begin{array}{c}\text { Auge tras la crisis del trabajo asalariado } \\
\text { en la gran empresa de los países europeos }\end{array}$ \\
\hline
\end{tabular}

Fuente: Draperi (2002)

11 Ya previamente, Vienney, había estudiado el funcionamiento del sistema capitalista en el crecimiento producido en la postguerra, cuando se produjo un debilitamiento de estas sociedades. 
Así, de la mano de, por un lado, Desroche y su proyecto cooperativo nacido bajo la necesidad de cambiar el orden económico social y, por otro, de Vienney que centró su atención en el funcionamiento y transformaciones de las cooperativas, resurgió con fuerza en los años 70 el intento por teorizar las características de las organizaciones de ES (Lévesque y Mendell, 2005).

No obstante, todavía en la actualidad continúan estos intentos por establecer un marco teórico de ES dando lugar a una diversidad de denominaciones afines como Economía Solidaria (Razeto, 1984; Laville, 1995, 2011; Singer, 2004; Coraggio, 2011), Tercer Sector (Levitt, 1973; Delors y Gaudin, 1979; Evers y Laville, 2004) o Sector no lucrativo (Newhouse, 1970; Weisbrod, 1975; Hansmann, 1980; Rose-Ackerman, 1986; Salamon y Anheier, 1992), entre otras.

\section{Elementos comunes de la ES y la economía solidaria: el desarrollo de un campo científico a partir de la evolución del pensamiento económico y de los movimientos sociales}

Como ya se ha señalado, el siglo XIX estuvo marcado por conflictos sociales constantes entre el Estado, la sociedad civil y la gran industria, lo que desencadenó importantes movimientos sociales y asociativos inspirados en pensadores como Saint-Simon, Owen o Fourier. Se trataron de movimientos asociacionistas, tanto para protestar contra los grandes patronos, organizados por ejemplo en sindicatos, como para constituirse en torno a un oficio aglutinando a patrones y obreros con el fin de evitar la desaparición del gremio y que funcionasen bajo criterios solidarios entre sus miembros, como es el caso de las cooperativas (Draperi, 2014).

Los precursores como Owen, King y Fourier han sido los inspiradores del cooperativismo moderno. Para llevar a cabo la conocida experiencia de la cooperativa de consumo Sociedad Equitativa de los Pioneros de Rochdale en 1844 y a partir de la cual se han construido los principios cooperativos que se conocen en la actualidad, sus fundadores siguieron las ideas de Robert Owen sobre la necesidad de reformar el capitalismo y mejorar las condiciones de vida de los trabajadores. No obstante, con el tiempo, el gran movimiento cooperativo y asociacionista que surgió en el siglo XIX fue apagándose (Sanyal, 1999).

Tras la Segunda Guerra Mundial, desde la postguerra hasta los años 70 y 80, en la Edad de Oro del capitalismo, el movimiento en torno a lo que podían ser consideradas organizaciones de ES era casi inexistente: el crecimiento económico exponencial acompañado de pleno empleo en la sociedad europea y con un importante papel del Estado como motor de desarrollo -Estado de Bienestar-, que intervenía en las cuestiones sociales para mantener el funcionamiento de un sistema basado en políticas keynesianas, llevó a niveles de bienestar marginando a este tipo de iniciativas.

Sin embargo, la crisis de los años 70 mermó este bienestar social de manera generalizada e hizo cuestionarse el sistema económico de entonces, abriendo paso al neoliberalismo. Así, el interés por las iniciativas de ES volvió a renacer en las tres últimas décadas del siglo $\mathrm{XX}$, periodo que puede ser caracterizado por un auge de estudios y prácticas sobre organizaciones que trabajaban bajo criterios de solidaridad. En los años 70, con la crisis económica, se produjo un nuevo fenómeno desconocido hasta entonces, la estanflación, denominado así por la fuerte inflación y el estancamiento del crecimiento económico con importantes tasas de desempleo estructural. A ello se sumó un Estado debilitado, asfixiado ahora por el gran incremento del gasto público para hacer frente a los grandes problemas estructurales de la sociedad europea (crisis del Estado de Bienestar), dando lugar a importantes colectivos sociales en riesgo de exclusión. Ante este contexto, resurgieron dinámicas solidarias entre diferentes actores para afrontar estos problemas desde diversas actividades y organizaciones sin necesariamente coincidir con las tradicionales de ES (Sanyal, 1999; Pérez de Mendiguren, Etxezarreta y Guridi, 2008, 2009).

Apareció así un empobrecimiento de gran parte de la sociedad europea. En este contexto, con un Estado debilitado, las asociaciones actuaron para luchar contra esta pobreza y exclusión social. Por ello, tuvo lugar un movimiento asociativo para responder al interés general, con un importante incremento del número de estas organizaciones que recibieron el apoyo y respaldo del Estado. Se puede decir que las relaciones entre el Estado y las asociaciones cambiaron del siglo XIX al XX, pasando de relaciones conflictivas a relaciones complementarias. A partir de entonces, la pobreza relacionada con la exclusión del mundo del trabajo sustituyó a la pobreza relacionada con la sobreexplotación obrera del siglo XIX. Ahora, esta pobreza era más vulnerable dado que -a diferencia del siglo XIX en el que se contó con los sindicatos y la huelga como instrumento de respuesta- no contaban en la realidad con ningún medio de reivindicación convirtiéndose así en una cuestión social significativa (Castel, 1995; Draperi, 2014).

Estas prácticas solidarias y nuevas iniciativas, con el apoyo del Estado y convertidas en acciones sociales, fueron denominadas por Eme y Laville (1994) como experiencias de Economía Solidaria al tratarse de actuaciones solidarias hacia los colectivos sociales en riesgo de exclusión.

En la misma década, al otro lado del continente europeo, en América, se estaban barajando diferentes enfoques relacionados con la ES como el de Economía Solidaria, Sector no lucrativo, Economía Popular, etc., respondiendo a diferentes contextos en el que se desarrollaron. Este intento de identificar o clasificar los 
diferentes enfoques existentes en torno a la ES, determinando sus diferencias, elementos comunes y considerando tanto la perspectiva científica como institucional, se ha realizado en diferentes estudios como los de Chaves y Monzón (2001), Guerra (2004), Monzón (2006), Pérez de Mendiguren, Etxezarreta y Guridi (2008, 2009), Draperi (2014) o Laville (2015).

Este trabajo se centra en el debate que suscita mayor discusión, el de ES versus Economía Solidaria (Laville, 2013; Draperi, 2014; Pérez de Mendiguren y Etxezarreta, 2015). Mientras que el concepto de ES es de origen europeo existiendo un mayor consenso acerca de qué debe entenderse como tal y las organizaciones que la forman, dado su reconocimiento institucional, para el enfoque de Economía Solidaria no ocurre esto. Este concepto ha iniciado su desarrollo tanto en Europa como en Latinoamérica.

Por un lado, la Economía Solidaria en Latinoamérica reconoce, al igual que la ES europea, que su nacimiento se produjo en el siglo XIX con precursores como Owen o Fourier y que incluye a las organizaciones más tradicionales -cooperativas, mutuas y asociaciones-. Por otro lado, la Economía Solidaria de origen europeo, particularmente francés, es diferente a esta concepción latinoamericana y, sobre todo, del enfoque de ES europeo: la Economía Solidaria, en su concepción francesa, se distingue de la ES, principalmente, en que no se basa en el agrupamiento de personas y en estatutos jurídicos como criterio de clasificación de sus organizaciones, sino en el origen de los recursos y la naturaleza de la actividad, pudiendo incluir otros campos empresariales jurídicos y excluir a las organizaciones tradicionales de la ES (Draperi, 2014).

Según Draperi (2014), la Economía Solidaria, desde la perspectiva francesa y por parte de los investigadores universitarios, se trata de defensores y profesionales de la acción social que ponen en marcha un proyecto empresarial para integrar a personas socialmente excluidas y que suelen ir acompañadas del apoyo de los poderes públicos, a diferencia de la concepción de ES que mantiene su independencia. Sin embargo, ésta -la ES- a diferencia de la Economía Solidaria, surge a partir de la asociación de un grupo de personas para cubrir necesidades en común y que pueden o no tener un beneficio de interés general además del colectivo de sus miembros.

Si se atiende al contexto en el que surgen estas concepciones, mientras que la ES nace alrededor de 1848 mediante la asociación de obreros para poner medios en común y ser decisores de su propio destino, entre otras motivaciones -constituyendo un concepto elaborado por los economistas que se populariza en los años 80 a través de las políticas socioeconómicas-, el concepto de Economía Solidaria es mucho más reciente dado que surge en Francia en los años 80 del siglo XX de la mano de los ya mencionados sociólogos Bernard Eme y Jean Louis Laville.

El concepto de Economía Solidaria emerge más bien de manera espontánea desde la sociedad civil, con matices y valores que van en contra de la economía ortodoxa (Laville, 1994), para responder a los problemas de exclusión, de individualismo y los ocasionados por la globalización económica, que presionan a la persona limitándola en cuanto a su libertad de acción. Al igual que la ES, reconoce a las asociaciones obreras del año 1848 pero incorporando otras motivaciones como las ecológicas o las feministas procedentes de los años 60 (Dacheux y Goujon, 2011). Es decir, mientras que la ES realiza actividades económicas definidas en los estatutos jurídicos de asociaciones, mutuas y cooperativas básicamente, la Economía Solidaria, desde su aparición en los años 80, realiza prácticas socioeconómicas generalizadas (Prades, 2012) que pueden o no coincidir con las fórmulas jurídicas reconocidas por la ES.

Según Draperi $(2011,2014)$, otra diferencia entre ambos enfoques europeos se plantea respecto a la relación de solidaridad: en la Economía Solidaria se enfoca desde las organizaciones hacia un colectivo con problemas de exclusión social entre otros, para dar respuesta a su situación; en la ES esta solidaridad se produce de manera interna entre los propios miembros de la organización, ya que el asociacionismo y la puesta en marcha de ésta deriva de unas necesidades comunes. De otra forma, la ES está basada en la unión social para responder a una situación de necesidad mediante la puesta en común de recursos como trabajo, herramientas, tiempo o recursos económicos, mientras que la Economía Solidaria focaliza sus objetivos, su acción solidaria, en la creación o reforzamiento del vínculo social sin que necesariamente exista una relación de reciprocidad directa entre los destinatarios de los servicios y los que ponen en marcha las acciones solidarias (Draperi, 2011, 2014) (Gráfico 3). 
Gráfico. 3. La acción solidaria en la Economía Solidaria y en la Economía Social

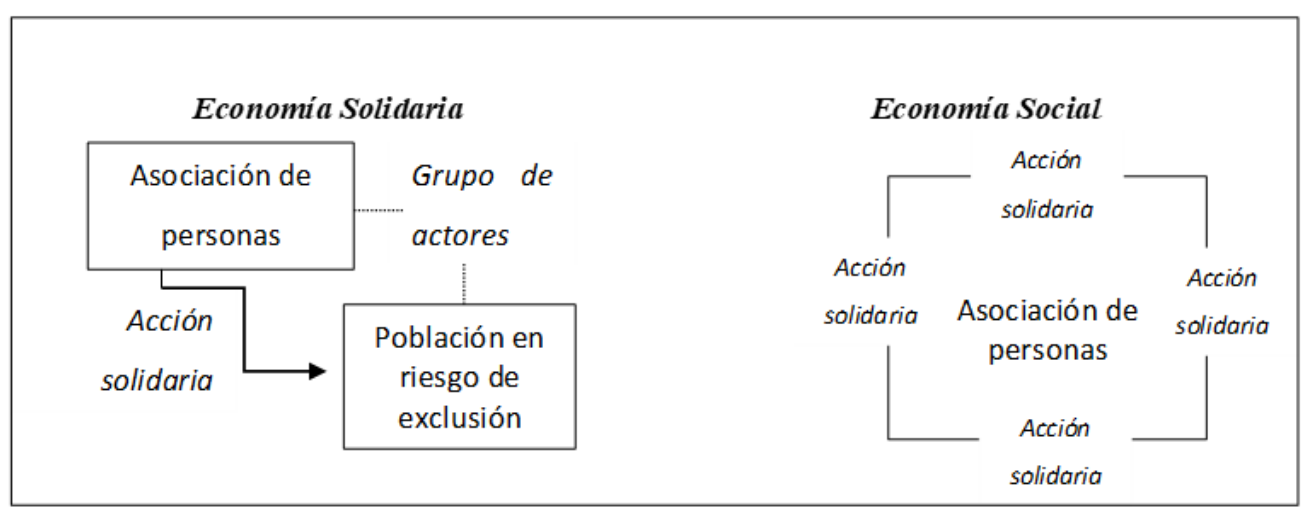

Fuente: Elaboración propia a partir de Draperi (2011).

Las principales críticas a la concepción europea de ES desde el enfoque de la Economía Solidaria han venido con los trabajos de Laville $(2011,2015)$ quien defiende que, aunque la Economía Solidaria tiene su base de desarrollo también en el movimiento cooperativo del siglo XIX, ampara unos principios y valores que han sido marginados por la preservación de una ES actual muy institucionalizada. Es por ello que, según el autor (Laville, 2011), la Economía Solidaria constituye una ampliación de la ES -formada por asociaciones, cooperativas y mutuas- y cuya función consiste en limitar el poder capitalista y lograr beneficios socioeconómicos más justos.

A pesar de las diferencias entre los dos enfoques, ambas concepciones ocupan un lugar en la actividad económica que las diferencian del resto: ofrecen respuestas a necesidades de carácter social (por ejemplo las cooperativas de vivienda) y antropológico (la ES en la sociedad o su reivindicación por la propiedad colectiva); no constituyen un modelo teórico en sí dentro de la ciencia económica ni de cualquier otra; y no se trata de experiencias ni cuantitativamente pequeñas -como el caso del Grupo Mondragón- ni desfasadas o antiguas, ni marginales (Prades, 2012). Es por ello que existe una cada vez mayor convergencia entre la ES y la Economía Solidaria, utilizándose este concepto de Economía Social y Solidaria tanto por parte de teóricos (Coraggio, 2011; Monzón y Chaves, 2012), como desde diferentes instituciones (como la Ley de ES y Solidaria de Francia ${ }^{12}$ o el RELIESS -Centro Internacional de referencia y enlace sobre Políticas Públicas en ES y Solidaria en Montreal-) (Pérez de Mendiguren y Etxezarreta, 2015).

Por otro lado, hay que destacar que, dada las múltiples nuevas experiencias que han ido surgiendo en diferentes contextos y sectores para adaptarse a nuevos procesos de renovación en los que su forma de organización no responde a una fórmula tradicional de ES -cooperativas, mutuas y asociaciones como tal-, hay autores que hablan de la "Nueva ES" (Defourny, Favreau y Laville, 1997; Tomas-Carpi, 1997; Coque y Pérez, 2002).

Finalmente, siguiendo a Pérez de Mendiguren y Etxezarreta (2015) se puede sostener que, a pesar del progresivo desarrollo del concepto de Economía Solidaria en los últimos años, el de ES cuenta con un mayor desarrollo, reconocimiento y consolidación institucional. La falta de un marco teórico unánime para la Economía Solidaria es fruto de la diversidad de experiencias socioeconómicas de las que surgen interpretaciones diferentes (Guerra, 2010; Coraggio, 2012). No obstante, ambas tienen el objetivo común de la emancipación social, aunque con acepciones diferentes, y de la economía democrática, haciendo especial reconocimiento sobre todo a personas que promueven el emprendimiento colectivo con fines de carácter social (Draperi, 2011).

\section{Consideraciones finales}

El concepto de ES, desde sus antecedentes históricos a lo largo de los siglos XVIII y XIX y hasta la actualidad, está en una evolución continua atendiendo y dando respuesta a las diferentes necesidades sociales, económicas, culturales, ambientales $\mathrm{y}$, en general, territoriales, vinculadas a las dinámicas evolutivas de las sociedades y de los diferentes contextos. Y todavía hoy, no se cuenta ni con un consenso en cuanto al término, ni en cuanto a su definición. En este sentido, se puede hablar de ES, Economía Solidaria,

12 La ley francesa designa a una serie de organizaciones como de ES y Solidaria (LOI $n^{\circ}$ 2014-856 du 31 juillet 2014 relative à l'économie sociale et solidaire).

https://www.legifrance.gouv.fr/affichTexte.do;jsessionid=F3F6FC032F2EDD797976AF8D2CC33491.tpdjo15v 2?cidTexte=JORFTEXT000029 313296\&categorieLien=id (Consultado el 08/01/2021). 
Sector no lucrativo o Economía Popular, entre sus numerosas variedades en torno a una serie de elementos y factores que ofrecen respuestas a necesidades sociales y económicas, con algunas particularidades en relación al contexto de referencia.

La situación y la evolución histórica han condicionado a la ES desde sus orígenes hasta la actualidad. Considerando sus inicios, a partir de los siglos XVIII-XIX, determinado por la existencia de serios conflictos socioeconómicos y escenarios inestables, surgen movimientos asociativos y de colaboración para hacer frente y dar respuesta a la precaria situación de los trabajadores, consecuencia de la intensificación de la competencia económica y de la producción en masa que había irrumpido en las economías con la Revolución Industrial.

La situación también fue cuestionada por el pensamiento económico de la época desde diferentes ideologías, contemplando el movimiento asociativo y el cooperativismo: el socialismo utópico representado por Charles Fourier, Henri de Saint-Simon y Robert Owen; el cristianismo humanista o social dirigido por Buchez y Fréderic Le Play; el cuaquerismo con Plockboy o Bellers; los socialistas ricardianos Thompson, Hodgskin y John Gray; el anarquismo con Proudhon o el marxismo con Marx. Desde otra perspectiva, y bajo la idea de que las sociedades cooperativas constituían una fórmula de adaptación al sistema capitalista más que de sustitución de este sistema económico, también hay que señalar la contribución de la escuela liberal del pensamiento neoclásico de la mano de Walras.

Todos los movimientos sociales y aportaciones desde el pensamiento económico en los siglos XVIII y XIX son desencadenantes de lo que hoy se conoce como ES o de otros conceptos afines.

En este sentido, no es de extrañar que el concepto de ES tuviera un gran impulso en Francia, a partir de las revoluciones de 1789 y la influencia de pensadores como Rousseau. A partir de esto, el periodo 18201860 estuvo marcado por una corriente de economistas que destacaban un enfoque social y moral de la economía, como es el caso de Dunoyer o Sismondi. Aunque no plantearon un marco teórico concreto para la ES, sus aportaciones constituyeron una base importante en la evolución del concepto al poner en valor que el núcleo de la economía es el hombre y no la riqueza en sí misma. Otros autores como Walras o Le Play también realizaron aportaciones sobre ES. Pero fue Gide, representante de la Escuela de Nîmes, bajo un pensamiento liberal con espíritu solidarista, quien comenzó a plantear el marco teórico de la ES e impulsó el movimiento cooperativo, sobre todo de consumo, en Francia.

Desde el cooperativismo de consumo, también destacaron Desroche y Vienney en el siglo XX, quienes fueron muy críticos con la economía capitalista. Sus obras, diferentes entre sí pero a la vez complementarias, avanzaron en la definición y configuración de la ES, intentando teorizar las características de sus organizaciones.

En la actualidad, uno de los principales debates vinculado con las diferentes acepciones y falta de consenso en la definición está en torno al concepto de ES versus Economía Solidaria que, aunque presentan algunos rasgos específicos o diferenciadores, ambas coinciden en la importancia de la emancipación social y la economía democrática, cuyas actuaciones están dirigidas a la consecución de fines de carácter social.

Por tanto, si bien no existe una única definición consensuada sobre el término de ES, todas ellas están sustentadas en un conjunto de valores y principios que configuran las actividades de lo que se entiende como ES y que están incorporados de manera expresa o indirecta en todas las definiciones sobre este concepto, poniéndose de manifiesto su importancia como núcleo en torno al cual gira la gestión y el funcionamiento de estas organizaciones.

Lo realmente importante es poner en valor su potencial y evitar su banalización: no es la definición, no es la discusión sobre qué se entiende en términos formales sobre ES, sino que lo que hay que revalorizar es su función social, económica, cultural, ambiental y territorial y su capacidad para cubrir las necesidades sociales de espacios vulnerables y escenarios de cambio, obtenida a lo largo del tiempo como respuesta a la evolución histórica de las sociedades.

También es de resaltar que, junto con las experiencias aplicadas y llevadas a cabo en diferentes contextos, progresivamente, surge también un desarrollo del marco teórico de la ES en el ámbito del pensamiento económico que se va consolidando dentro de la rama económica, a lo largo del tiempo. Así, en el estudio e interpretación de la evolución seguida por la ES, hay que profundizar en estas dos variables señaladas como elementos determinantes de su evolución: el avance en su marco conceptual dentro del pensamiento económico, por un lado, y su respuesta dada a los movimientos sociales vinculados a la evolución histórica, por otro.

Por tanto, este movimiento, que puede parecer ambiguo y un poco disperso por la falta de consenso en cuanto a su denominación y definición, surge y sigue teniendo sentido en un escenario de cambio, con nuevos retos socioeconómicos y con un factor determinante en sus respuestas: el ámbito social. De hecho, es probable que en el contexto actual derivado de la crisis de la pandemia, la ES vuelva a "resurgir" de manera importante por su posible capacidad de resiliencia y de respuesta a las necesidades sociales. Esta capacidad de respuesta constituye uno de los elementos claves que explican su evolución a lo largo de la historia, adquiriendo importancia, este movimiento de la ES, especialmente cuando han tenido lugar situaciones socioeconómicas desfavorables. 
En este trabajo se ha identificado y se ha puesto en valor de manera sistemática la evolución seguida, tanto en el pensamiento económico como en los movimientos sociales, desde los siglos XVIII y XIX, de lo que podría considerarse como el surgimiento y la base de la ES actual, proporcionando un marco histórico de referencia para comprender su concepto en el presente.

A partir de este artículo pueden derivarse nuevas líneas de investigación en las que se vincule el impacto de otros elementos o factores que han incidido en la historia de las sociedades y de los territorios, en el ámbito de la ES, de sus principios y de sus valores, profundizando en su función social y en su capacidad de dinamizar el desarrollo territorial, sobre todo en contextos de cambio.

\section{Referencias bibliográfícas}

ACI, Alianza Cooperativa Internacional (1995) Identidad cooperativa: nuestros principios y valores. https://www.ica.coop/es/cooperativas/identidad-alianza-cooperativa-internacional. (Consultado el 22/03/2021).

Alonso, M. (1999) Pensamiento económico y economía social. Valencia: Tirant lo Blanch.

Audigier, M. (2014) L'Économie sociale d'hier à aujourd'hui. Paris: Ellipses.

Breton, Y. (2000) Itinéraire de Gide dans la période précédant la publication des Principes d'économie politique en 1884. En: Gide, C. Principes d'économie politique. Comité pour l'édition des œuvres de Charles Gide. Paris: L'Harmattan, pp. 7-59.

Castel, R. (1995) Les métamorphoses de la question sociale: une chronique du salariat. Paris: Fayard.

Chanial, P. y Laville, J.L. (2001) Économie sociale et solidaire: le modèle français. http://www.unites.uqam.ca/econos/Chercheurs-Laville-Chanial.pdf. (Consultado el 25/11/2020).

Chaves, R. y Monzón, J. L. (2001) Economía social y sector no lucrativo. Actualidad científica y perspectivas. CIRIECEspaña Revista de economía pública, social y cooperativa, $\mathrm{N}^{\circ} 37$, pp. 7-23.

Chaves, R. (1999) La economía social como enfoque metodológico, como objeto de estudio y como disciplina científica. CIRIEC-España, Revista de Economía Pública, Social y Cooperativa, № 33, pp. 115-139.

Cole, G. (1964) Historia del pensamiento socialista, I. Los precursores, 1789-1850. México: Fondo de Cultura Económica (FCE).

Coque, J. y Pérez, E. (2002) La nueva Economía Social: otra forma de hacer negocios. Revista Valenciana de Economía y Hacienda, $\mathrm{N}^{\circ} 4$, pp. 157-175.

Coraggio, J.L. (2011) Economía Social y Solidaria. El trabajo antes que el capital. Quito: Abya-Yala.

Coraggio, J.L. (2012) Las tres corrientes vigentes de pensamiento y acción dentro del campo de la Economía Social y Solidaria (ESS): Sus diferentes alcances. http://www.socioeco.org/bdf/es/corpus document/fiche-document2124.html. (Consultado el 12/10/2020).

Dacheux, E. y Goujon, D. (2011) Principes d'économie solidaire. Paris: Ellipses.

Defourny, J. (1992) Orígenes, contextos y funciones de un tercer gran sector. En: Monzón J.L.y Defourny, J. Economía Social. Entre Economía Capitalista y Economía Pública. Valencia: CIRIEC-España, pp. 17-39.

Defourny, J., Favreau, L. y Laville, J.L. (1997) Inserción y nueva Economía Social. Un balance internacional. Valencia: CIRIEC-España.

Delors, J. y Gaudin, J. (1979) Pour la création d'un troisième secteur, comment créer des emplois. Paris: Centre de recherche Travail et Société.

Demoustier, D. (2002) Une lecture française: L'analyse proposée par Claude Vienney est-elle encore pertinente aujourd'hui? En: cahier coordonné par André Chomel. Coopération et économie sociale au «second»XXe siècle. Claude Vienney (1929-2001). Paris: L'Harmattan, pp. 103-107.

Demoustier, D. (2006) Débats autour de la notion d'Économie Sociale. RECMA, Revue Internationale de l'Économie Sociale, $\mathrm{N}^{\circ} 300$, pp. 8-18.

Desroche, H. (1976) Le projet cooperatif; son utopie et sa pratique, ses appareils et ses reseaux, ses esperances et ses deconvenues. Paris: les Éd. Ouvrières.

Desroche, H. (1983) Pour un traité d'économie sociale. Paris: CIEM

Divar, J. (2010) Reflexiones: Peter Cornelius Plockboy y la República Cooperativa. REVESCO, Revista de Estudios Cooperativos, $\mathrm{N}^{\circ} 102$, pp. 145-153.

Divar, J. (2011) Las cooperativas: una alternativa económica. Madrid: Dykinson.

Draperi, J.F. (2011) L'économie sociale et solidaire: une réponse à la crise? Capitalisme, territoires et démocratie. Paris: Dunod.

Draperi, J.F. (2014) Comprendre l'économie sociale. Fondements et enjeux. Paris: Dunod.

Eme, B. y Laville, J.L. (1994) Cohésion sociale et emploi. Paris: Desclée de Brouwer.

Evers, A. y Laville, J.L. (2004) The Third Sector in Europe, Cheltenham: Edward Elgar.

Fauquet, G. (1965) Euvres. Paris: Institut des Études Coopératives.

Gaminde, E. (2017) La doctrina social cristiana y el cooperativismo vasco: una alternativa para el cambio. Madrid: Dykinson.

García, J., Via, J. y Xirinacs, L.M. (2006) La dimensión cooperativa. Economía Solidaria y Transformación Social. Barcelona: Icaria.

Gide, C. (1924) Les Sociétés coopératives de consommation. Paris: Recueil Sirey. 
Gide, C. (1955) Curso de Economía Política. Buenos Aires: El Ateneo.

Gide, C. (2000) Principes d'économie politique. Comité pour l'édition des œuvres de Charles Gide. Paris: L'Harmattan.

Guerra, P. (2004) Economía de la Solidaridad. Una introducción a sus diversas manifestaciones teóricas. http://tacuru.ourproject.org/documentos/guerra.pdf. (Consultado el 11/11/2020).

Guerra, P. (2010) La Economía Solidaria en Latinoamérica. Papeles de relaciones ecosociales y cambio global, № 110 , pp. 67-76.

Hansmann, H. (1980) The Role of Nonprofit Enterprise. The Yale Law Journal, Vol. 89, No5, pp. 835-910. DOI: https://doi.org/10.2307/796089.

Landreth, H. y Colander, D.C. (2006) Historia del pensamiento económico. Madrid: McGraw-Hill España.

Laserre, G. (1972) El cooperativismo. Barcelona: Oikos-tau.

Laville, J.L. (1994) L'Économie solidaire. Une perspective internationale. Paris: Desclée de Brouwer.

Laville, J.L. (1995) L'économie solidaire: une nouvelle forme d'économie sociale? Revue des études coopératives, mutualistes et associatives, 255(53), pp. 70-80.Lavuk

Laville, J.L (2011) L'Économie Solidaire. Paris: CNRS Éditions.

Laville, J.L. (2013) Économie sociale et solidaire, capitalisme et changement démocratique. En: Hiez, D., y Lavillunière E. (dir). Vers une théorie de l'économie sociale et solidaire. Paris: Editions Larcier, pp.17-32.

Laville, J.L. (2015) Asociarse para el bien común. Tercer Sector, Economía Social y Economía Solidaria. Barcelona: Icaria.

Lévesque, B., y Mendell, M. (2005) L’économie sociale: diversité des définitions et des constructions théoriques. Revue Interventions économiques. Papers in Political Economy, 32. DOI: https://doi.org/10.4000/interventionseconomiques.852.

Levitt, T. (1973) The Third Sector-New Tactics for a Responsive Society. New York: Division of American Management Associations.

Malo, M.C. (2003) La cooperación y la Economía social. En Chaves, R. et al., Economía Social. Precisiones conceptuales y algunas experiencias históricas. Buenos Aires: Fundación OSDE, pp. 197-230.

Martínez, A. (2013) Cooperativismo y economía del bien común. Boletín de la Asociación Internacional de Derecho Cooperativo, No 47, pp. 185-198. DOI: https://doi.org/10.18543/baidc-47-2013pp185-198.

Merino, S. (2005) Los orígenes del cooperativismo moderno y el socialismo premarxista. GEZKI, No 1, pp.169-188.

Monzón, J.L. (2003) El cooperativismo en la historia de la literatura económica. CIRIEC-España, Revista de Economía Pública, Social y Cooperativa, № 44, pp. 9-32.

Monzón, J.L. (2006) Economía Social y conceptos afines: fronteras borrosas y ambigüedades conceptuales del Tercer Sector. CIRIEC-España, Revista de Economía Pública, Social y Cooperativa, No 56, pp. 9-24.

Monzón, J.L y Chaves, R. (2012) La Economía Social en la Unión Europea. Bruselas: Comité Económico y Social Europeo.

Moreau, J. (2002) Penser la coopération dans un contexte transformé. En cahier coordonné par André Chomel. Coopération et économie sociale au «second»XXe siècle. Claude Vienney (1929-2001). Paris: L'Harmattan, pp. 911.

Newhouse, J. (1970) Toward a theory of nonprofit institutions: an economic model of a hospital. American Economic Review, $N^{\mathrm{o}} 60$, pp. 64-73.

Pénin, M. (1997) Charles Gide 1847-1932. L'esprit critique. Paris: L'Harmattan.

Pérez de Mendiguren, J.C. y Etxezarreta, E. (2015) Sobre el concepto de Economía Social y Solidaria: aproximaciones desde Europa y América Latina. Revista de Economía Mundial, № 40, pp. 123-144.

Pérez de Mendiguren, J.C., Etxezarreta, E., y Guridi, L. (2009) Economía Social, Empresa Social y Economía Solidaria: diferentes conceptos para un mismo debate. Papeles de Economía Solidaria, No 1, pp. 1-41.

Pérez de Mendiguren, J.C.; Etxezarreta, E. y Guridi, L. (2008) ¿De qué hablamos cuando hablamos de Economía Social y Solidaria? Concepto y nociones afines. Comunicación presentada a las XI Jornadas de Economía Crítica, Bilbao, 27-29 marzo.

Prades, J. (2012) L'utopie réaliste. Le renouveau de l'expérience coopérative. Paris: L'Harmattan.

Quijano, J.E. y Reyes, J.M. (2006) Historia y doctrina de la cooperación. Colombia: Universidad Cooperativa de Colombia.

Razeto, L. (1984) Economía de solidaridad y mercado democrático. Santiago de Chile: Ediciones PET.

Rose-Ackerman, S. (Ed.). (1986) The economics of non profit institutions: Studies in structure and policy. Oxford: Oxford University Press.

Salamon, L.M. and Anheier, H.K. (1992) In search of the Nonprofit Sector I: The question of definitions. Working Paper, $\mathrm{N}^{\mathrm{o}}$ 2, Johns Hopkins University.

Sanyal, B. (1999) Potentiel et limites du développement «par le bas». En: Defourny, J., Develtere, P. y Fonteneau, B. L'économie sociale au Nord et au Sud. De Boeck Supérieur, pp. 179-194.

Singer, P. (2004) Economía solidaria. En: Cattani A. D., La otra economía. Buenos Aires: Altamira, pp. 199-212.

Tomas-Carpi, J.A. (1997) Prospects for a Social Economy in a changing world. Annals of Public and Cooperative Economics, Vol. 68, No 2, pp. 247-279. DOI: https://doi.org/10.1111/1467-8292.00045.

Vienney, C. (1980) Socio-économie des organisations coopératives, tome 1: formation et transformations des institutions du secteur coopératif français. Paris: Coopérative d'information et d'édition mutualiste. 
Vienney, C. (1982) Socio-économie des organisations coopératives, tome 2: analyse comparée des coopératives fonctionnant dans des systèmes socio-économiques différents. Paris: Coopérative d'information et d'édition mutualiste.

Weisbrod, B.A. (1975) Toward a theory of the voluntary nonprofit sector in a three sector economy. En: Phelps, E. Altruism, morality and economic theory. New York: Russell Sage Foundation. 